\title{
Clinical Implications and Impact of Discovery of the Thyroid Hormone Receptor on Integrin $\alpha \mathrm{v} \beta 3-\mathrm{A}$ Review
}

\author{
Aleck Hercbergs* \\ Department of Radiation Oncology, Cleveland Clinic, Cleveland, OH, United States
}

Hypothyroidism has been reported to improve survival in cancer patients but only recently has the putative mechanism been identified as a receptor for thyroxine and tri-iodothyronine on integrin $\alpha \vee \beta 3$. Recognition of divergence of action of the pro-oncogenic L-thyroxine (T4) from pro-metabolic 3,5,3'-triiodo-L-thyronine (T3) has enabled clinical implementation whereby exogenous T3 may replace exogenous (or endogenous) T4 to maintain clinical euthyroid hypothyroxinemia that results in significantly better survival in advanced cancer patients without the morbidity of clinical hypothyroidism.

OPEN ACCESS

Edited by:

Sandra Incerpi,

Roma Tre University, Italy

Reviewed by:

Roberto De Luca,

Beth Israel Deaconess Medical Center and Harvard Medical School,

United States

Hynda K. Kleinman,

George Washington University,

United States

*Correspondence:

Aleck Hercbergs

hercbergs@gmail.com

Specialty section:

This article was submitted to

Cancer Endocrinology,

a section of the journal

Frontiers in Endocrinology

Received: 13 May 2019

Accepted: 02 August 2019

Published: 23 August 2019

Citation:

Hercbergs A (2019) Clinical Implications and Impact of Discovery of the Thyroid Hormone Receptor on

Integrin $\alpha v \beta 3-A$ Review.

Front. Endocrinol. 10:565

doi: 10.3389/fendo.2019.00565
Keywords: cancer, euthyroid hypothyroxinemia, hypothyroidism, integrin $\alpha \mathrm{v} \beta 3$, L-thyroxine, thyroid hormone receptor

\section{INTRODUCTION}

In recent years there have been reports that blood thyroxine depletion in individuals with advanced solid cancers-e.g., glioblastoma, high grade soft tissue sarcoma, was associated with regression of advanced tumors. Exogenous 3,5,3' -triiodo-L-thyronine (L-T3) was used to maintain metabolic euthyroidism $(1,2)$.

How did this approach come about?

The 1993 report of spontaneous remission (3) and 5-year survival of a patient with metastatic non-small cell lung cancer inspired this novel line of research, which has evolved from early experimental studies to the clinic, wherein proactive medically induced thyroid suppression was investigated in the treatment of failed high grade brain tumors (glioblastoma multiforme) (4). Significant prolongation of life (from 4 to 10 months median survival) was associated with a drop of $>40 \%$ of circulating free thyroxine (T4) levels. Tumor regression was also observed in patients. There was short survival in all of the $50 \%$ of patients who did not experience free thyroxine depletion. The delay in thyroid hormone decrease remained an obstacle in extended implementation of this approach until the discovery by Davis and Mousa et al. of a newly identified cell surface receptor for thyroid hormone (both analogs T4 and T3) on integrin $\alpha v \beta 3$ expressed on cancer cell membranes and actively dividing vascular endothelium (5).

This contribution is not intended as a comprehensive review of the literature of thyroid hormones and cancer but is focused on relevance of thyroxine impact on cancer growth and biology, now understood to be mediated through the cell surface integrin $\alpha \mathrm{v} \beta 3$ receptor.

\section{THYROID HORMONE IN PHYSIOLOGY AND CANCER BIOLOGY}

\section{T4 and T3-A Pivotal Difference and Roles}

The use of exogenous T3 as a substitute for T4 as thyroid hormone replacement has enabled withdrawal of the potent pro-oncogenic hormone $\mathrm{T} 4$ in cancer patients without resulting in clinical hypothyroidism (1). 
In the absence of T4, cancer cell mitogenesis and proliferation does not occur. Absence of T3 impacts severely mitogenesis and metabolism. The pivotal role of thyroid hormones thyroxine T4 and $\mathrm{T} 3$ in cancer growth and biology and the impact on emerging clinical practice has become understood following identification of integrin $\alpha v \beta 3$ and the interaction with and binding differences between T3 and T4 (1). T4 is the principal secretory product of the thyroid gland. It serves as a prohormone for T3 in the latter's intracellular functions (1). The reported literature refers solely to blood thyroid hormone levels individually, e.g., FT4 or FT3 and/or TSH or under the "hypothyroid" label.

T3-directed gene expression in cells requires primary interactions between T3 and its nuclear receptor proteins (TRs) $(1,2)$. T3 also regulates mitochondrial respiration (3). Because its biological half-life is significantly longer than that of T3 (6), $\mathrm{T} 4$ is the most commonly prescribed form of thyroid hormone replacement for clinical hypothyroidism and for suppression of endogenous pituitary thyrotropin (TSH) (1).

It is becoming accepted that cancer depends on both analogs to exist, survive, proliferate, and grow into tumors. Thyroxine is the sole endogenous and pleiotropic pro-oncogenic hormone that abets cancer, acting as a ligand for the membrane expressed receptor on integrin $\alpha \mathrm{v} \beta 3$ (7).

Thyroid hormone is a pivotal crucial pro-growth prooncogenic hormone for most if not all malignant tumors and the crucial interaction of T4 is with the integrin $\alpha v \beta 3$. Thyroid hormone drives and is pro-proliferation and pro-angiogenic for cancer (7-9).

It will become evident how this discovery has led to a new and novel paradigm in understanding and management of solid cancers.

Thyroxine is the more potent pro-oncogenic thyroid hormone analog and is the pro-hormone for $\mathrm{T} 3$, which is the dominant pro-metabolic thyroid hormone $(10,11)$. T3 and T4 bind to the plasma membrane protein integrin $\alpha v \beta 3$, which mediates the signal across the membrane (5). T4 is active at this receptor
$(7,11)$. In vitro evidence indicates that $\mathrm{T} 3$, bound with a lower affinity by $\alpha v \beta 3$ (7), is of low activity at physiological levels at the receptor.

Integrin $\alpha v \beta 3$ contains two thyroid hormone binding sites, S1 and S2, which activate different downstream pathways (12): S1 binds T3 and activates the PI3K/AKT-pathway whereas S2 binds T4 and, with lower affinity, T3, and activates PI3K/AKTpathway and MAPK-pathway. At physiological concentrations, T4 (and not T3) is the principal ligand at S2. Thyroid hormone action at $\alpha \mathrm{v} \beta 3$ is inhibited by the deaminated and decarboxylated T4 derivative tetrac (3,3,5',5'-tetraiodothyroacetic acid) (5). Blocking the thyroid hormone receptor on the integrin (equivalent to total thyroxine depletion) downregulates multiple pro-oncogenic genes and upregulates pro-apoptotic genes (12). The consequences of tetrac on human xenograft growth and a triple negative breast cancer gene expression are profoundly anti-oncogenic $(12,13)$.

Thyroid hormone is therefore a high priority molecule promoting interaction with tumor cell membranes and is not tumor specific. The pursuit of strategies to implement "precision" medicine is clearly irrelevant here.

\section{Genomic vs. Non-genomic Actions of Thyroid Hormone}

Classical effects of thyroid hormones are initiated when T3 binds to its TRs that interact with specific responding elements (TREs). Thyroid hormones can also elicit their actions by a non-classical mechanism without direct gene transcription regulation by nuclear TRs (Figure 1). These non-genomic actions indirectly modulate gene transcription by activating intracellular pathways and other transcription factors (10, 14). Many of the non-genomic actions are via a receptor expressed on a membrane integrin for thyroxine and T3. The availability of T4 is the crucial step for activation of the integrin and consequent trans-membrane signaling into the cell (Figure 2). Total withdrawal or depletion of T4 will arrest this entire process

A

Mechanisms of Thyroid Hormone Actions

Genomic actions are initiated in the cell nucleus by interactions of T3 with its nuclear receptor proteins (TRs) and consequent gene transcription.

Nongenomic actions are initiated at the plasma membrane or in cytoplasm and may culminate in gene transcription or in extranuclear cellular events.

B

Nongenomic Actions Directed from the Cell Surface by Thyroid Hormone

1. Activation of specific kinases-such as ERKs-and kinase translocation to the nucleus with $\mathrm{TR}$, estrogen receptor, p53

2. Complex ERK- or PI3-K-mediated intracellular/cellular events that reflect interfaces between nongenomic and genomic actions, e.g., tumor cell proliferation and angiogenesis

3. Local cell surface events: control of activities of ion transporters

FIGURE 1 | (A) Actions of thyroid hormone are genomic or non-genomic in mechanism. (B) Specific non-genomic actions. 


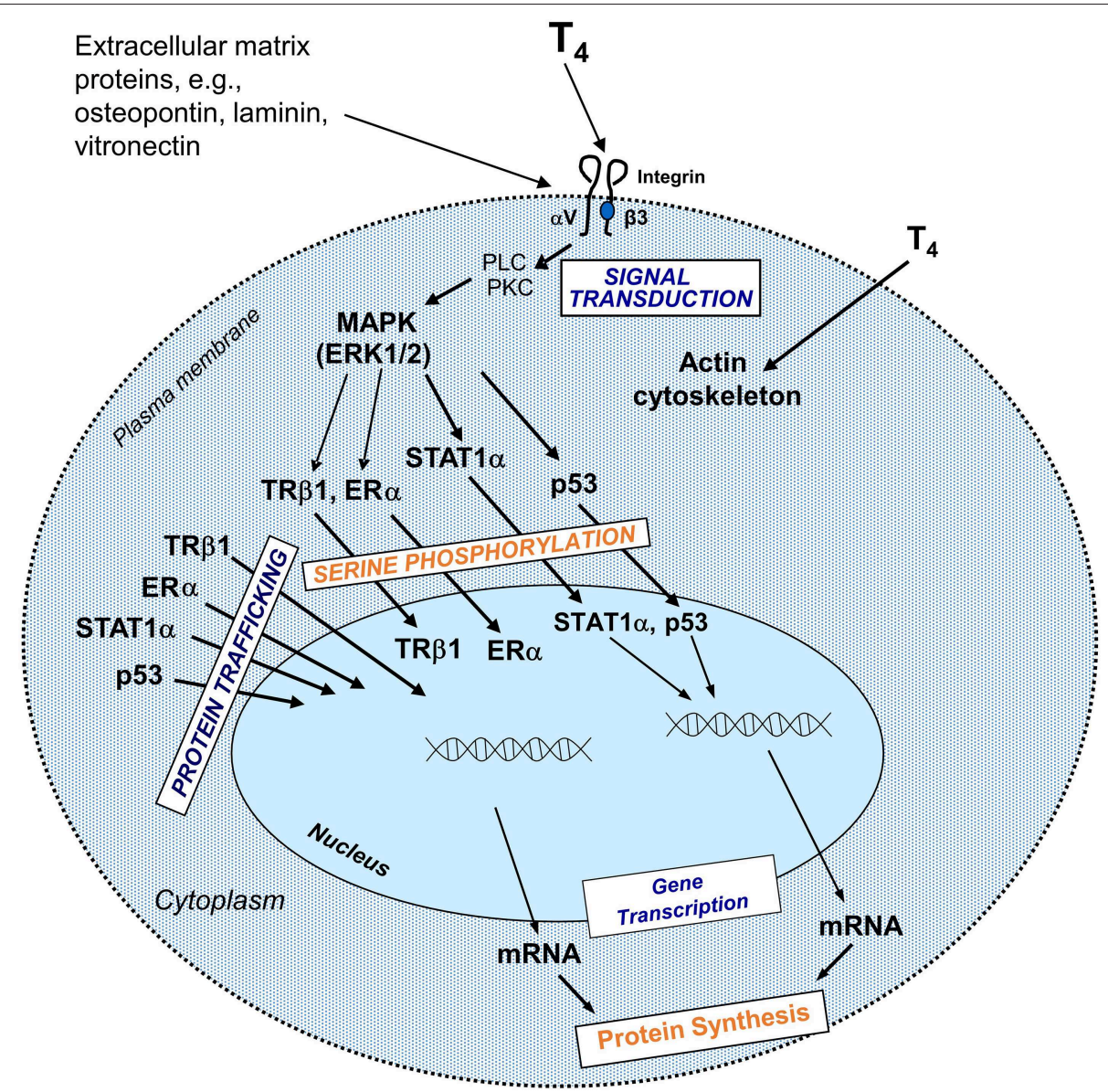

FIGURE 2 | Non-genomic actions of the hormone that begin at integrin $\alpha \vee \beta 3$ include regulation of intracellular trafficking of specific proteins to the nucleus and serine phosphorylation of some of these proteins in the course of nuclear entry. Directed to the nucleus from the cytoplasm, some of these proteins might be involved in modulation of transcription of specific genes and in cell proliferation. These pathways depend on activation of phospholipase C (PLC), protein kinase C (PKC), mitogen activated protein kinase (MAPK)1, and MAPK2. T4 non-genomically rapidly activates actin polymerization in hypothyroid astocytes and osteoblastic cells (15).

Reprinted with permission from Hercbergs et al. (16).

with consequences for the viability of the tumor and/or vascular cell (11).

\section{THYROID HORMONE, CANCER, AND THE INTEGRIN $\alpha v \beta 3$-EXPRESSED THYROID HORMONE RECEPTOR}

\section{T4 as a Hormone}

Observations of thyroid hormone's impact on cancer prognosis predate the discovery of the integrin $\alpha \mathrm{v} \beta 3$ and thyroid hormone receptor on cancer cells and membranes and vascular endothelium. These studies are summarized in Table 1.

The discovery of the receptor and activation by thyroxine and significantly less by T3 has led to successful clinical translation and implementation in the treatment of compassionate care cancer patients by simple substitution of exogenous T3 for exogenous L-thyroxine in hypothyroxinemia. Discovery of the thyroid hormone receptor on integrin $\alpha v \beta 3$ advances the understanding of the interaction and relationship to cancer with ambient thyroid hormone levels (1).

\section{T4 and Cancer Biology}

$\mathrm{T} 4$ in physiological free hormone concentrations stimulates proliferation of cancer cells in vitro and in xenografts (13, 3945). Preclinical studies of tetrac, which blocks thyroid hormone action at integrin $\alpha v \beta 3$, have shown arrested tumor growth $(7,11)$ in a variety of tumor xenografts including xenografts of renal cell carcinoma (13), non-small cell lung carcinoma (46), medullary carcinoma of the thyroid (41), pancreatic carcinoma (43), and multi-drug resistant breast cancer (47).

\section{CLINICAL TRANSLATIONAL STUDY TO INDUCE EUTHYROID HYPOTHYROXINEMIA}

\section{Euthyroid Hypothyroxinemia and Divergence of Action Between T4 and T3}

This is a eumetabolic state maintained in the total absence of blood thyroxine by providing exogenous T3. The individual can therefore live and perform all normal daily activities and 
TABLE 1 | Cancer outcomes across a spectrum of thyroid functions.

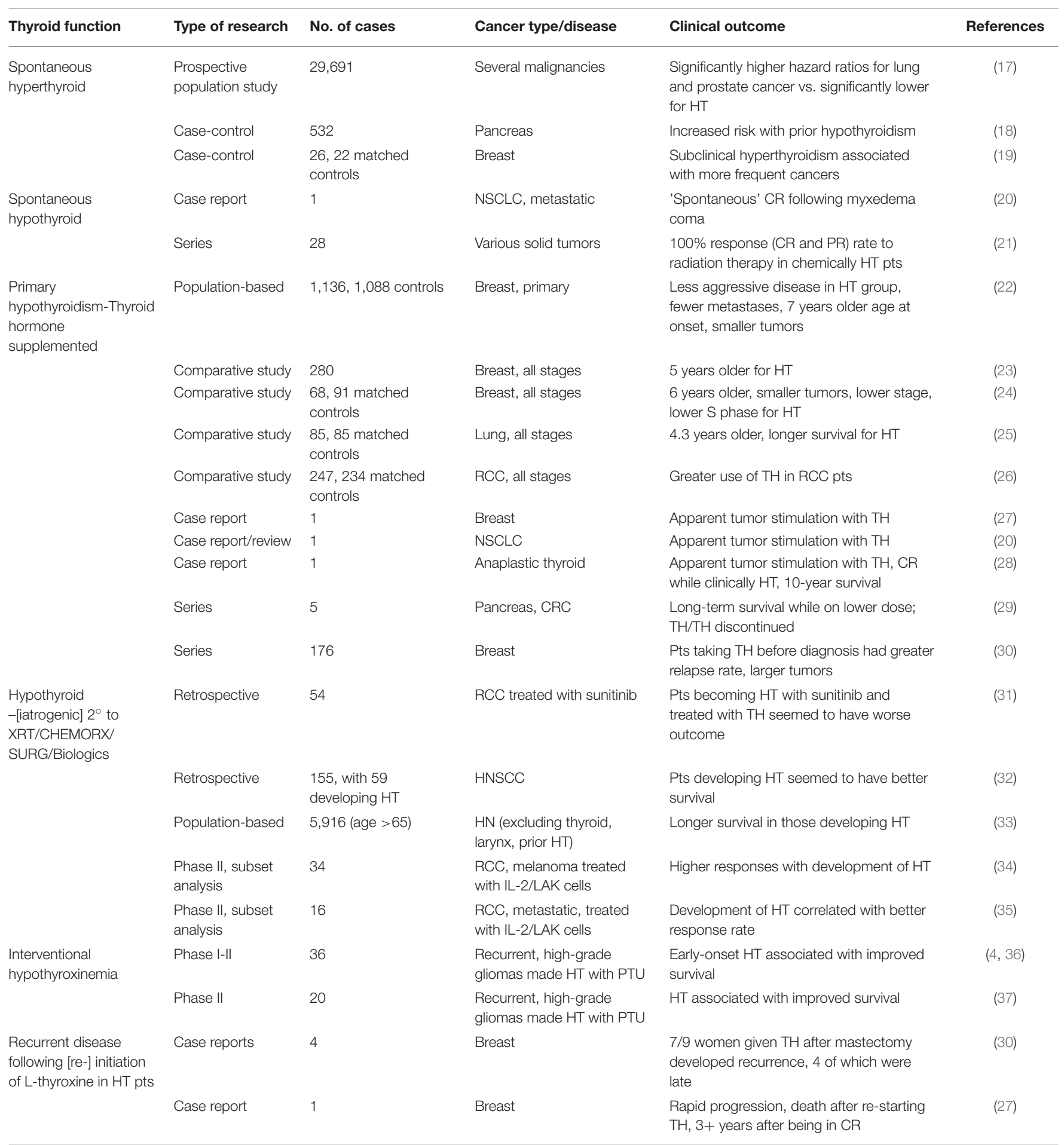

CR, complete response; CRC, colorectal cancer; HN, head and neck; HNSCC, head and neck squamous cell carcinoma; HT, hypothyroidism; IL-2, interleukin 2; LAK, lymphokineactivated killer; NSCLC, non-small cell lung cancer; PR, partial response; pts, patients; PTU, propylthiouracil; RCC, renal cell carcinoma; TH, thyroid hormone; XRT, radiation therapy. Reprinted with permission from Hercbergs et al. (38).

functions as prior to removal of the source of T4 or post total thyroidectomy. Preclinical evidence (12) indicates that T3, bound with a lower affinity by $\alpha \mathrm{v} \beta 3$ (9), is of low activity at physiological levels at the receptor $(5,39)$. The clinical ramifications of these effects on cancer cells are supported by the results of induction of the state of euthyroid hypothyroxinemia in patients with advanced cancers and with normal thyroid function (1). 


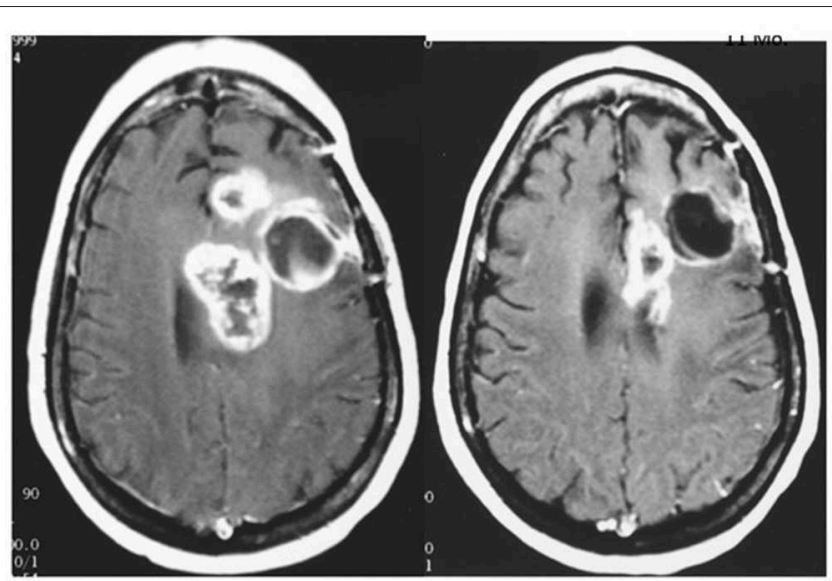

FIGURE 3 | MRI of brain of a 42 year old female with recurrent glioblastoma showing significant mass reduction with free thyroxine depletion at 4 months. Left, pre-thyroxine depletion; right, 4 months later. The patient survived for 3 years. Reprinted with permission from Hercbergs et al. (4).

In a compassionate-need study of terminal patients with a variety of incurable solid tumors, extended survival was observed in a majority of patients using exogenous T3 to induce and maintain hypothyroxinemia. T3 administration prevented symptomatic hypothyroidism. Low odds of survival were surmounted in 19 of 23 patients (83\%) who exceeded the expected median survival of literature-reported series used as controls (1). An additional approach is to terminate exogenous T4 supplementation to allow the T4 level to decline and supplement with T3 titrated individually to the patient's functional needs. Examples of the outcomes of this strategy on advanced disease (glioblastoma and sarcoma) are shown in Figures 3-5.

\section{CLINICAL STUDIES}

Clinical studies have shown that survival is significantly prolonged (almost 3-fold) in failed glioblastoma patients treated with propylthiouracil to inhibit thyroxine synthesis.

More information available about T4 action on lung cancer is limited, but euthyroid hypothyroxinemia appears to slow the course of and extend survival of non-small cell, small cell lung, pancreas, mesothelioma, glioblastoma, and soft tissue sarcoma $(1,2)$.

Going forward it is suggested and clinically pivotal that the term hypothyroxinemia be employed and not the clinically imprecise term hypothyroidism, which is misleading in the emerging era as shown in this paper.

\section{DISCUSSION}

The identification of the pro-oncogenic exogenous thyroxine and its replacement by the metabolically dominant T3 has had a significant impact on the palliation and survival of advanced cancer patients, who live longer. This discovery followed identification of the integrin $\alpha v \beta 3$ thyroid hormone receptor and lower binding of $\mathrm{T} 3$ than $\mathrm{T} 4$. There is also divergence of signaling pathways between the pro-metabolic T3 and the pro-oncogenic T4 (8).

Tetrac is a specific molecular blocker of the thyroid hormone receptor on integrin $\alpha v \beta 3$ and is anti-oncogenic. The effects of tetrac occlusion of the receptor reveal the pleiotropic prooncogenic unopposed T4 effect on mitogenesis, angiogenesis, and apoptosis (48).

Both T3 and T4 ligand have a receptor on the cancer cell plasma membrane and on dividing vascular endothelial cells. This receptor on integrin $\alpha v \beta 3$ is activated to transduce mitogenic signaling to the interior of the cell. Similarly, blocking of the receptor with tetrac effectively blocks all (most) T4 and T3 signal transduction as occurs following T4 and T3 depletion. This results in regression of established tumors, inhibits angiogenesis, and potentiates ionizing radiation-induced cell death (2). Separation and divergence of the effects and functions of T4 from T3 on integrin $\alpha \mathrm{v} \beta 3$-expressed receptors occurs as a result of binding to the receptor. T4 is significantly more potent than T3 (48) on cancer and blood vessel cells, as noted above.

T4 depletion with use of an antithyroid drug such as methimazole eliminates circulating T4 and T3, whether the latter is derived from T4 in the peripheral circulation or directly released by the thyroid gland. This approach has been utilized in cancer patients with considerable efficacy, resulting in significant prolongation of survival and tumor regression in some patients with large tumor masses, e.g., GBM and soft tissue sarcoma (1).

A rare spontaneous regression of metastatic lung cancer has occurred whereby T4 and T3 became depleted to life threatening levels with myxedema coma (3).

It is of note that there is a declining continuum of risk for free thyroxine levels from high supraphysiological (hyperthyroidism) to frank hypothyroxinemia and to blocking of the integrin $\alpha v \beta 3$ thyroid hormone receptor, which would equate to a zero ambient free T4.

\section{FUTURE DIRECTIONS}

The capacity/ability to impact on cancer progression in the occult or preclinical stage with only a molecular diagnosis and identification by altering endogenous thyroid hormone (thyroxine) levels might become a minimally morbid, but effective, treatment approach to pre-emptively treat solid tumor types prior to their emergence as clinically evident disease.

\section{SUMMARY}

Discovery of integrin $\alpha v \beta 3$ receptor and binding to the thyroid hormone ligand have led to the strategy of rapid T4 depletion of the pro-oncogenic stimulus of T4 both in the euthyroid and exogenous T4 supplemented individuals. A significantly faster release from $\mathrm{T} 4$ driven tumor growth has resulted in rapid tumor regression, with palliation in life threatening situations and better survival. The discovery of tetrac binding to the receptor promises even greater therapeutic gains. The wide range of tumor types responding to T4 depletion suggests there is potential for globally impacting on cancer from the very early 

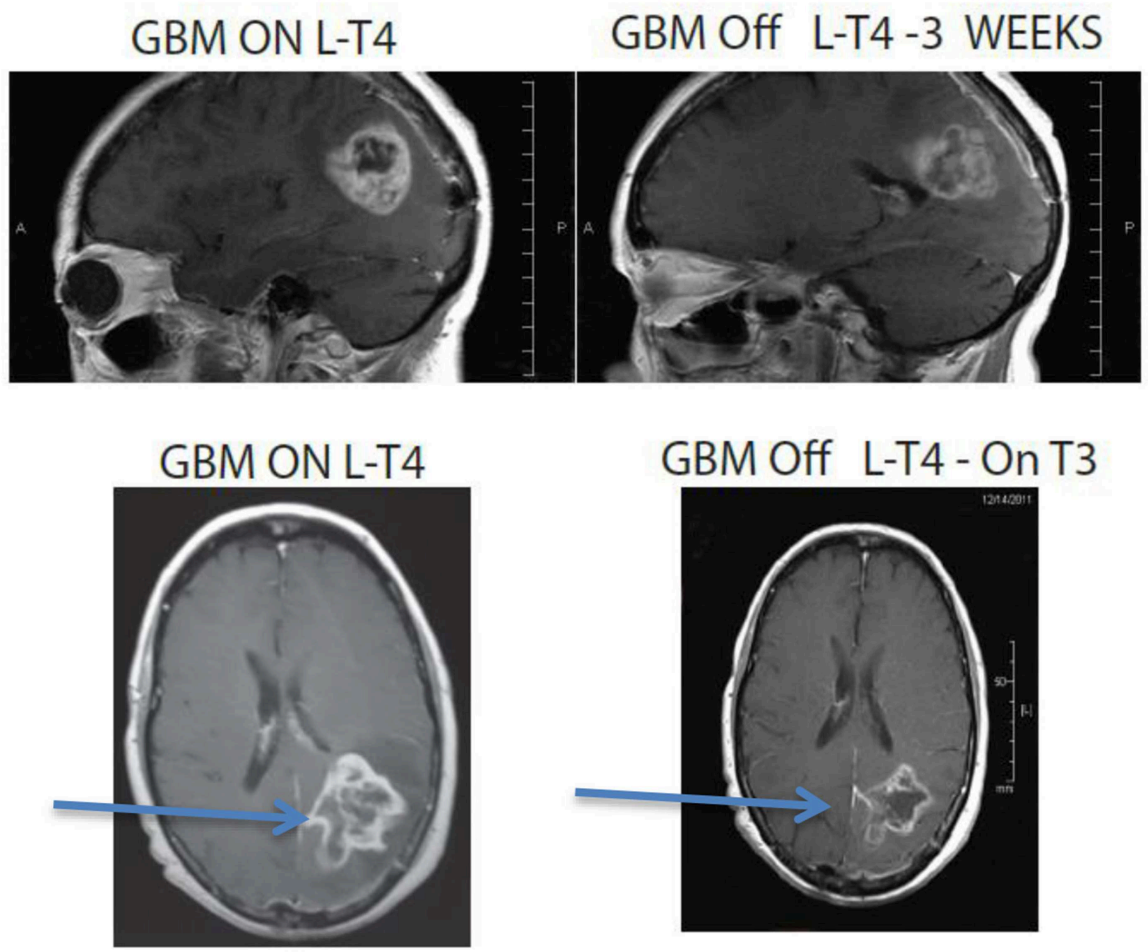

ON L-T4

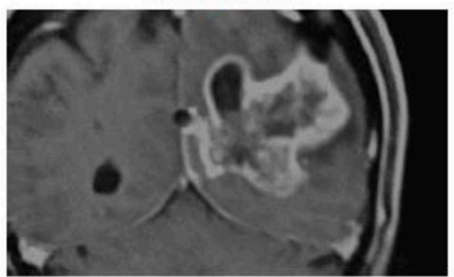

Off L-T4-3 On T3

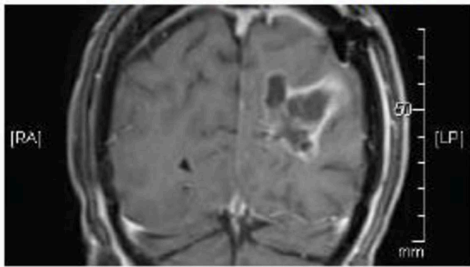

FIGURE 4 | MRI images of a 67 year old female patient who was deteriorating neurologically with hemiplegia unresponsive to high dose dexamethasone.

Discontinuation of L-T4 was followed within 1 week by significant clinical improvement and tumor regression. Arrows point to tumor mass, showing reduction in size in all dimensions following cessation of exogenous L-T4.

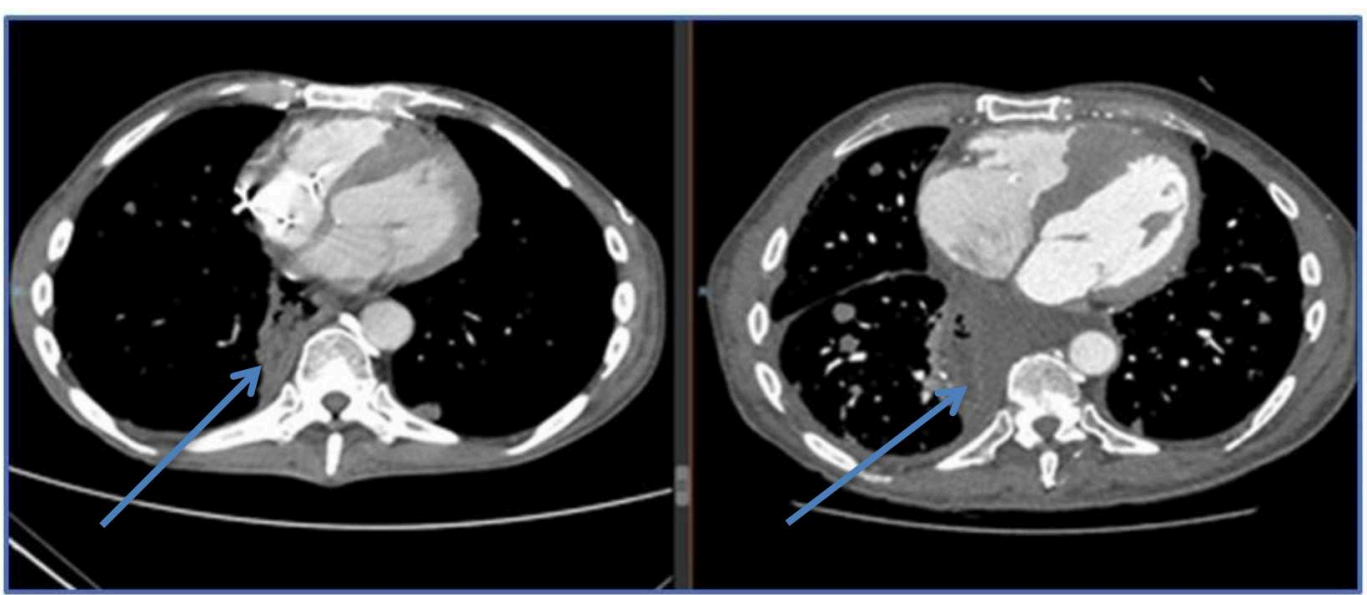

FIGURE 5 | CT images of esophageal sarcoma metastatic with cardiac infiltration and cardiac failure, right image is on exogenous L-T4, left image is post L-T4 discontinuation and oral cyclophosphamide. Patient improved clinically and was discharged from intensive care. 
to late stages. It is rational to consider application of this approach to much earlier states of cancer and thereby prolong survival significantly.

\section{CONCLUSION}

Identification of the integrin $\alpha v \beta 3$ receptor pathway promises a paradigm changing approach to manage and treat cancer more effectively than currently available modalities.

\section{REFERENCES}

1. Hercbergs A, Johnson RE, Ashur-Fabian O, Garfield DH, Davis PJ. Medically induced euthyroid hypothyroxinemia may extend survival in compassionate need cancer patients: an observational study. Oncologist. (2015) 20:72-6. doi: 10.1634/theoncologist.2014-0308

2. Hercbergs A, Davis PJ, Lin H-Y, Keating KA, Mousa SA. Thyroid Hormone Replacement Therapy in Patients with Various Types of Cancer. in Hormone Therapy and Replacement in Cancer and Aging-related Diseases. InTechOpen (2019). Available online at: https://cdn.intechopen.com/pdfs/ 67201.pdf

3. Hercbergs A, Leith JT. Spontaneous remission of metastatic lung cancer following myxedema coma-an apoptosis-related phenomenon? J Natl Cancer Inst. (1993) 85:1342-3. doi: 10.1093/jnci/85.16.1342

4. Hercbergs AA, Goyal LK, Suh JH, Lee S, Reddy CA, Cohen BH, et al. Propylthiouracil-induced chemical hypothyroidism with high-dose tamoxifen prolongs survival in recurrent high grade glioma: a phase I/II study. Anticancer Res. (2003) 23:617-26.

5. Bergh JJ, Lin HY, Lansing L, Mohamed SN, Davis FB, Mousa S, et al. Integrin $\alpha \mathrm{V} \beta 3$ contains a cell surface receptor site for thyroid hormone that is linked to activation of mitogen-activated protein kinase and induction of angiogenesis. Endocrinology. (2005) 146:2864-71. doi: 10.1210/en. 2005-0102

6. Jonklaas J, Bianco AC, Bauer AJ, Burman KD, Cappola AR, Celi FS, et al. Guidelines for the treatment of hypothyroidism: prepared by the American Thyroid Association Task Force on thyroid hormone replacement. Thyroid. (2014) 24:1670-751. doi: 10.1089/thy.2014.0028

7. Davis PJ, Davis FB, Mousa SA, Luidens MK, Lin HY. Membrane receptor for thyroid hormone: physiologic and pharmacologic implications. Annu Rev Pharmacol Toxicol. (2011) 51:99-115. doi: 10.1146/annurev-pharmtox-010510-100512

8. Lin HY, Sun M, Tang HY, Lin C, Luidens MK, Mousa SA, et al. LThyroxine vs. 3,5,3'-triiodo-L-thyronine and cell proliferation: activation of mitogen-activated protein kinase and phosphatidylinositol 3-kinase. Am. J. Physiol. Cell Physiol. (2009) 296:C980-91. doi: 10.1152/ajpcell.00305.2008

9. Davis PJ, Glinsky GV, Lin HY, Leith JT, Hercbergs A, Tang HY, et al. Cancer cell gene expression modulated from plasma membrane integrin $\alpha \mathrm{v} \beta 3$ by thyroid hormone and nanoparticulate tetrac. Front Endocrinol. (2014) 5:240. doi: $10.3389 /$ fendo. 2014.00240

10. Brent GA. Mechanisms of thyroid hormone action. J Clin Invest. (2012) 122:3035-43. doi: 10.1172/JCI60047

11. Davis PJ, Goglia F, Leonard JL. Nongenomic actions of thyroid hormone. Nat Rev Endocrinol. (2016) 12:111-21. doi: 10.1038/nrendo.2015.205

12. Glinskii AB, Glinsky GV, Lin HY, Tang HY, Sun M, Davis FB, et al. Modification of survival pathway gene expression in human breast cancer cells by tetraiodothyroacetic acid (tetrac). Cell Cycle. (2009) 8:3562-70. doi: $10.4161 / c c .8 .21 .9963$

13. Yalcin M, Bharali DJ, Lansing L, Dyskin E, Mousa SS, Hercbergs A, et al. Tetraidothyroacetic acid (tetrac) and tetrac nanoparticles inhibit growth of human renal cell carcinoma xenografts. Anticancer Res. (2009) 29:3825-31.

14. Cayrol F, Sterle HA, Diaz Flaque MC, Barreiro Arcos ML, Cremaschi GA. Non-genomic actions of thyroid hormones regulate the growth

\section{AUTHOR CONTRIBUTIONS}

The author confirms being the sole contributor of this work and has approved it for publication.

\section{ACKNOWLEDGMENTS}

The author thanks Kelly A. Keating of the Pharmaceutical Research Institute, Albany College of Pharmacy and Health Sciences, Rensselaer, NY for her editing of the manuscript.

and angiogenesis of T cell lymphomas. Front Endocrinol. (2019) 10:63. doi: 10.3389/fendo.2019.00063

15. Silva FG, Giannocco G, Santos MF, Nunes MT. Thyroid hormone induction of actin polymerization in somatotrophs of hypothyroid rats: potential repercussions in growth hormone synthesis and secretion. Endocrinology. (2006) 147:5777-85. doi: 10.1210/en.2006-0110

16. Hercbergs A, Davis PJ, Lin HY, Mousa SA. Possible contributions of thyroid hormone replacement to specific behaviors of cancer. Biomed Pharmacother. (2016) 84:655-9. doi: 10.1016/j.biopha.2016.09.053

17. Hellevik AI, Asvold BO, Bjoro T, Romundstad PR, Nilsen TI, Vatten LJ. Thyroid function and cancer risk: a prospective population study. Cancer Epidemiol Biomarkers Prev. (2009) 18:570-4. doi: 10.1158/1055-9965.EPI-08-0911

18. Ko AH, Wang F, Holly EA. Pancreatic cancer and medical history in a population-based case-control study in the San Francisco Bay Area, California. Cancer Causes Control. (2007) 18:809-19. doi: 10.1007/s10552-007-9024-6

19. Saraiva PP, Figueiredo NB, Padovani CR, Brentani MM, Nogueira CR. Profile of thyroid hormones in breast cancer patients. Braz J Med Biol Res. (2005) 38:761-5. doi: 10.1590/S0100-879X2005000500014

20. Hercbergs A. Spontaneous remission of cancer-a thyroid hormone dependent phenomenon? Anticancer Res. (1999) 19:4839-44.

21. Hercbergs A. High tumor response rate to radiation therapy in biochemically hypothyroid patients (Abstract \#167). In: Proceedings of AACR. (San Diego, CA) 248 .

22. Cristofanilli M, Yamamura Y, Kau SW, Bevers T, Strom S, Patangan M, et al. Thyroid hormone and breast carcinoma - primary hypothyroidism is associated with a reduced incidence of primary breast carcinoma. Cancer. (2005) 103:1122-8. doi: 10.1002/cncr.20881

23. Backwinkel K, Jackson AS. Some features of breast cancer + thyroid deficiency - report of 280 cases. Cancer. (1964) 17:1174. doi: 10.1002/10970142(196409)17:9<1174::AID-CNCR2820170913>3.0.CO;2-C

24. Hercbergs A, Daw H, Thakur S. Primary hypothyroidism and breast cancer: clinical and pathological risk reduction correlates from a case control study (Abstract \# 178). In: Proceedings of the 80th Annual Meeting of the American Thyroid Association. (Palm Beach, FL) (2009).

25. Hercbergs A, Mason J, Reddy C. Thyroid hormones and lung cancer: primary hypothyroidism is prognostically significant for survival in lung cancer (abstract \#4440). In: 95th Annual Meeting, AACR. (Orlando, FL) (2004).

26. Rosenberg AG, Dexeus F, Swanson DA, Von Eschenbach AC. Relationship of thyroid disease to renal cell carcinoma. An Epidemiol Study Urol. (1990) 35:492-8. doi: 10.1016/0090-4295(90)80101-R

27. Hercbergs A. The thyroid gland as an intrinsic biologic responsemodifier in advanced neoplasia - a novel paradigm. In Vivo. (1996) 10:245-7.

28. Hercbergs A, Setrakian S, Abdelmannan D. Anaplastic thyroid CA: 10year survival in a man with uncorrected primary hypothyroidism. Thyroid. (2007) 17:S-93.

29. Hercbergs A, Daw H, Ayoub W. Possible association of hypothyroidism with longevity in advanced colorectal and pancreatic cancer: a case study. In: 79th Annual Meeting of American Thyroid Association. (Chicago, IL: Thyroid) (2008). 
30. Burt J, Schapira D. Thyroid hormone: a modifier of the natural history of breast cancer (Abstract \# 738). In: Annual Meeting of the American Association for Cancer Research. (San Diego, CA) (1983).

31. Sabatier RGG, Deville, J. Hypothyroidism and survival during sunitinib therapy in metastatic renal cell cancer: a prospective observational analysis (Abstract \# 317). In: ASCO Genitourinary Cancers Symposium. (Orlando, FL) (2009).

32. Nelson M, Hercbergs A, Rybicki L, Strome M. Association between development of hypothyroidism and improved survival in patients with head and neck cancer. Arch Otolaryngol-Head Neck Surgery. (2006) 132:1041-6. doi: 10.1001/archotol.132.10.1041

33. Smith GL, Smith BD, Garden AS, Rosenthal DI, Sherman SI, Morrison $\mathrm{WH}$, et al. Hypothyroidism in older patients with head and neck cancer after treatment with radiation: a population-based study. Head Neck. (2009) 31:1031-8. doi: 10.1002/hed.21066

34. Atkins MB, Mier JW, Parkinson DR, Gould JA, Berkman EM, Kaplan MM. Hypothyroidism after treatment with interleukin-2 and lymphokine-activated killer cells. N Engl J Med. (1988) 318:1557-63. doi: 10.1056/NEJM198806163182401

35. Weijl NI, Vanderharst D, Brand A, Kooy Y, Vanluxemburg S, Schroder J, et al. Hypothyroidism during immunotherapy with interleukin-2 Is associated with antithyroid antibodies and response to treatment. J Clin Oncol. (1993) 11:1376-83. doi: 10.1200/JCO.1993.11.7.1376

36. Hercbergs ASJ, Reddy C, Goyal L. Early onset propylthiouracil-induced hypothyroidism is associated with improved survival in recurrent high grade glioma (Abstract \# 1211). In: 99th Annual Meeting AACR. San Diego, CA (2008).

37. Linetsky E, Hercbergs A, Dotan S. Time to tumor progression (TTP) and quality of life (QOL) following propylthiouracil induction of chemical hypothyroidism in failed malignant gliomas (Abstract \# 144). In: World Federation of Neuro-Oncology - Second Quadrennial Meeting. (Edinburgh) (2005).

38. Hercbergs AH, Ashur-Fabian O, Garfield D. Thyroid hormones and cancer: clinical studies of hypothyroidism in oncology. Curr Opin Endocrinol Diabetes Obes. (2010) 17:432-6. doi: 10.1097/MED.0b013e32833d9710

39. Davis FB, Tang HY, Shih A, Keating T, Lansing L, Hercbergs A, et al. Acting via a cell surface receptor, thyroid hormone is a growth factor for glioma cells. Cancer Res. (2006) 66:7270-5. doi: 10.1158/0008-5472.CAN05-4365

40. Lin HY, Tang HY, Shih A, Keating T, Cao G, Davis PJ, et al. Thyroid hormone is a MAPK-dependent growth factor for thyroid cancer cells and is anti-apoptotic. Steroids. (2007) 72:180-7. doi: 10.1016/j.steroids.2006. 11.014
41. Yalcin M, Dyskin E, Lansing L, Bharali DJ, Mousa SS, Bridoux A, et al. Tetraiodothyroacetic acid (tetrac) and nanoparticulate tetrac arrest growth of medullary carcinoma of the thyroid. J Clin Endocrinol Metab. (2010) 95:1972-80. doi: 10.1210/jc.2009-1926

42. Meng R, Tang HY, Westfall J, London D, Cao JH, Mousa SA, et al. Crosstalk between integrin $\alpha \mathrm{v} \beta 3$ and estrogen receptor- $\alpha$ is involved in thyroid hormone-induced proliferation in human lung carcinoma cells. PLoS ONE. (2011) 6:e27547. doi: 10.1371/journal.pone.0027547

43. Yalcin $M$, Lin HY, Sudha $T$, Bharali DJ, Meng R, Tang HY, et al. Response of human pancreatic cancer cell xenografts to tetraiodothyroacetic acid nanoparticles. Horm Cancer. (2013) 4:176-85. doi: $10.1007 /$ s12672-013-0137-y

44. Hsieh M-T, Wang L-M, Changou CA, Chin Y-T, Yang Y-CSH, Lai H-Y, et al. Crosstalk between integrin $\alpha \mathrm{v} \beta 3$ and $\mathrm{ER} \alpha$ contributes to thyroid hormoneinduced proliferation of ovarian cancer cells. Oncotarget. (2016) 8:24237-49. doi: 10.18632/oncotarget.10757

45. Lin HY, Chin YT, Yang YC, Lai HY, Wang-Peng J, Liu LF, et al. Thyroid hormone, cancer, and apoptosis. Compr Physiol. (2016) 6:1221-37. doi: $10.1002 /$ cphy.c150035

46. Mousa SA, Yalcin M, Bharali DJ, Meng R, Tang HY, Lin HY, et al. Tetraiodothyroacetic acid and its nanoformulation inhibit thyroid hormone stimulation of non-small cell lung cancer cells in vitro and its growth in xenografts. Lung Cancer. (2012) 76:39-45. doi: 10.1016/j.lungcan.2011.10.003

47. Bharali DJ, Yalcin M, Davis PJ, Mousa SA. Tetraiodothyroacetic acid-conjugated PLGA nanoparticles: a nanomedicine approach to treat drug-resistant breast cancer. Nanomedicine. (2013) 8:1943-54. doi: $10.2217 / \mathrm{nnm} .12 .200$

48. Lin HY, Cody V, Davis FB, Hercbergs AA, Luidens MK, Mousa SA, et al. Identification and functions of the plasma membrane receptor for thyroid hormone analogues. Discov Med. (2011) 11:337-47.

Conflict of Interest Statement: The author declares that the research was conducted in the absence of any commercial or financial relationships that could be construed as a potential conflict of interest.

The handling editor declared a past co-authorship with the author.

Copyright $\odot 2019$ Hercbergs. This is an open-access article distributed under the terms of the Creative Commons Attribution License (CC BY). The use, distribution or reproduction in other forums is permitted, provided the original author $(s)$ and the copyright owner(s) are credited and that the original publication in this journal is cited, in accordance with accepted academic practice. No use, distribution or reproduction is permitted which does not comply with these terms. 